The 16th Economic International Conference

New Challenges and Opportunities for the Economy 4.0,

May 7-8th, 2020, Suceava, Romania

\title{
A Comparative Analysis of the Housing Affordability in Romania and the European Union from the Perspective of the Housing Costs
}

\author{
Luminita-Mirela LĂZĂRESCU, Daniela Liliana DIACON \\ https://doi.org/10.18662/lumproc/ncoe4.0.2020/09
}

How to cite: Lăzărescu, L.-M., \& Diacon, D.L. (2020). A Comparative Analysis of the Housing Affordability in Romania and the European Union from the Perspective of the Housing Costs. In C. Nastase (vol. ed.), Lumen Proceedings: Vol. 13. 16th Economic International Conference NCOE 4.02020 (pp. 93-104). Iasi, Romania: LUMEN Publishing House.

https://doi.org/10.18662/lumproc/ncoe4.0.2020/09 


\title{
A Comparative Analysis of the Housing Affordability in Romania and the European Union from the Perspective of the Housing Costs
}

\author{
Luminita-Mirela LĂZĂRESCU1', Daniela Liliana DIACON²
}

\begin{abstract}
The accessibility of housing is one of the challenges to which the global economy, and implicitly, the European economy, must respond from the perspective of ensuring sustainable socio-economic development of contemporary society. This challenge is the result of problems whose manifestation has been accentuated in the last decades: increasing the rate of housing deprivation, limiting the access to housing for some social categories, emphasizing social exclusion and segregation. This study aims to identify, after a comparative analysis of the indicators associated with housing costs in the European Union and Romania, the main problems facing our country, as a state of the European Union, from the perspective of housing affordability. The research focuses on the study of bousing conditions and the aspects that define the housing affordability in Romania and the European Union. Romania has a housing stock dominated by houses $70.3 \%$ of homes built before 1980), but which is not burdened by major deficiencies (regarding the number of homes, number of rooms, living space). The deficiencies of housing in Romania are related to overcrowding and severe housing deprivation. In terms of housing costs, the research showed a high degree of burden on Romanian households with housing costs, among the highest in the EU, seven out of ten bouseholds feel the financial burden of housing costs and only 6\% of households are not affected. Data provided by Eurostat for the period 2010-2018 were used for the analysis.
\end{abstract}

Keywords: housing conditions; housing affordability; housing costs; burden; housing deprivation.

1 „Stefan cel Mare" University, Suceava, Romania, laz lumi@yahoo.com

2 „Stefan cel Mare" University, Suceava, Romania, diacon dana@yahoo.com 


\section{Introduction}

Housing affordability is considered to be an important determinant of a country's development and socio-economic stability [1]. The economic dimension of housing accessibility issues has been brought to public attention in recent decades by several problems that go beyond the state level and involve an integrated economic approach, continental and global: concentrating the population in attractive urban areas from the perspective of supply of jobs and services; lack of physical spaces for residential development in cities; the continuous increase of the sale and rental prices of the houses; low rate of housing construction relative to existing housing demand; the widening gap between income levels coupled with rising housing costs is causing an increasing share of the world's population to feel the financial pressure of housing costs; the differences in the level of development existing between the states of the world and between the regions, localities of the same state; increasing the poverty of the population and drastically limiting the possibilities of access to adequate housing, etc. The combination of rising housing costs and incomes has led, more and more households to devote an increasing share of disposable income to housing [1] and thus be forced to limit their spending on otherlife-relevant issues regarding the quality of life: education, health, culture, entertainment, clothing, etc. These constraints influence, in the first place, personal life, how individuals relate to society and are accepted by it, which generates multiple consequences at a social level (social exclusion, segregation, violence, maladaptation), at economic level (diminishing demand for certain services and goods on the market, limiting access to education, diminishing economic performance) and, in some cases, even at the political level (conflicts, political and economic instability, the inability of the state to implement social and economic policies that lead to an increase in the quality of life and housing).

\section{Problem Statement}

Research on housing affordability is a relative concern recent international study dating back to the last decades of the twentieth century and which has emerged from the scope of overall research on living conditions. The phrase "housing affordability" is polysemous in meaning, because it is used to describe several components of housing needs such as housing conditions, housing costs, housing quality, household income, and overcrowding [2]. The literature review shows that the term "housing 
affordability" has been approached, over time, both from the perspective of a household's ability to bear the costs of purchasing a home and from the perspective of the ability to support housing expenses. Affordability implies the ability of households to pay the costs of housing without imposing constraints on living costs. [3] According to Eurostat's definition, the housing costs include mortgage or housing loan interest payments for owners and rent payments for tenants and utilities (water, electricity, gas, and heating) and any costs related to regular maintenance and structural insurance. [4] Another direction of research exploited by many researchers is to define the concept concerning the ability of the household to bear the costs of purchasing a home. The term "housing affordability" simply implies the ability to purchase housing. [g] Furthermore, the difficulty in making precise use of the concept in a way that is generally accepted is directly linked with the imprecise and changing definitions of housing cost and income, and with a lack of easily analytical and computable techniques that could be readily applied. [3]

Despite consensus across Europe on housing affordability being increasingly stretched, the idea of what is affordable is subject to national interpretations.Therefore, in conceptualizing housing affordability, the social, economic, and ecological aspects that determine household well being must be considered.[1]

The issue of housing in Eastern European countries has been widely debated in the housing literature, especially in terms of the transformations induced in the housing sector during the transition period and has been reported, most often in the European context. The current situation of access to housing is, for each state of the European Union, the result of a combination of a complex of cultural, social, political, and economic factors that have generated its context of evolution. One of the gaps relevant to this study is the lack of a comparative analysis of housing affordability in Romania and the European Union for the current period (last decade). This analysis would make it possible to establish Romania's current gap with the European Union in terms of housing affordability.

\section{Research Questions}

With the current financial and economic crisis putting increasing pressure on the budget of European households, the issue of housing affordability raises increasing concern at the European level. [5] After 30 years of transition and over a decade of European integration, important changes have taken place in Romania that has favorably or unfavorably 
influenced access to housing, both from the perspective of buying homes and the ability of households to support housing costs.

The study aims to compare the situation of Romania with the European Union, in the period 2010-2018, in terms of access to affordable housing. We start from the idea that, although housing has improved in general, the affordability of housing marked a negative trend during this period.The study aims to answer questions such as:,, What are the problems facing the housing sector in Romania concerning the existing situation in the European Union?”; „What is the reality of housing accessibility in Romania and what evolution trends can be identified concerning those existing in the European Union?". Identifying weaknesses and formulating recommendations for improving access to affordable housing can be a starting point for changing housing policies in Romania and orienting them towards meeting the current needs of the population in terms of housing.

\section{Research Methods}

The research focused on comparing the statistical data available in the Eurostat database on living conditions (especially those associated with housing affordability) for the EU (European Union 28 countries) and Romania, to highlight the main problems of the HA in our country from 2010-2018. In the documentation stage, numerous articles of specialty have been consulted to become familiar with the meaning of the concept, with the associated terminology and to choose a way of approaching that best serves the purpose of the research. The study was structured in two parts: a part that analyzes the conditions in which housing takes place in Romania compared to those in the EU and a part that aims to compare the burden of households with housing costs in Romania and the EU. To draw the overall picture on living conditions in Europe, statistical data were processed regarding the number and characteristics of dwellings (forms of ownership, typology of dwelling); the utilities to which the houses have access; occupancy rate; deprivation of housing. To highlight the differences between Romania and the EU in terms of housing costs, indicators related to the burden of housing costs were used. The graphical representations were elaborated with the help of the Microsoft Excel program and were the basis of the interpretive approach and the formulation of the study conclusions. The statistical data for the mentioned indicators were taken from the Eurostat database, for the period 2010-2018. 


\section{Findings}

\subsection{Romania and the EU - comparison of current housing characteristics}

Between 2010 and 2018, the evolution of the number of dwellings registered, in Romania, an ascending trend, the home insurance rate is 492 homes/1000 people in Romania, being comparable to the one in the EU-28, which is $458 / 1000$ people.

In 2018 , over $96 \%$ of Romania's population lived in a privately owned dwelling, and only one in ten homeowners lived in a dwelling for which the payment loans does not exist, while in the European Union only seven out of ten residents own their home, $26.5 \%$ of the properties being encumbered by loans. We also note the low share of people in Romania living in rented homes $(3.6 \%)$ compared to those in the EU which amount to $30.7 \%$.

Thus, it can be appreciated that a large part of the dwellings in Romania and the EU have exceeded their period of use (or are close to this moment). According to statistical data provided by Eurostat, $70.3 \%$ of the households in Romania and $66.4 \%$ of those in the EU were built before 1980 (11.2\%, respectively $22.3 \%$ just before 1946$)$.

Regarding the typology of dwellings both in Romania and in the EU, in 2018, in the structure of the housing fund, the houses have a higher share (66.6\%, respectively $57.4 \%$ ) compared to that of the apartments $(33,4 \%$ and $41.9 \%$, respectively). In Romania, detached houses $(65.2 \%)$ have dominant shares compared to semi-detached ones $(1.4 \%)$, while in the EU the two categories have comparable values (34.6\% and 22.9\%). Between 2010 and 2018 , it can be appreciated that, in Romania, the ratio of houses/apartments has changed by decreasing the share of apartments (by 4\%) in the total number of dwellings, in favor of individual houses, while the structure at European level has remained more stable.

In 2010, the average area of a dwelling in was $96,4 \mathrm{~m}^{2}$ in the EU (the maximum value being $141 \mathrm{~m}^{2}$, in Cyprus, and the minimum value is registered in Romania $-43.9 \mathrm{~m}^{2}$ ). In 2018, Romania has registered the highest value of the overcrowding rate of housing among the EU Member States, of $46.3 \%$, compared to the EU average of only $2 \%$.

The analysis of the access to utilities of the completed houses between 2010 and 2018, indicates the fact that, in Romania, 99.66\% of newly built homes are supplied with electricity; $87,27 \%$ are connected to the running water network; $72.85 \%$ to the sewerage network; $96.08 \%$ have central heating, $17,97 \%$ use solid fuel stoves for heating) and between the two 
residential environments, the houses in urban areas are better equipped than those in rural areas.

The rate of housing deprivation registers, in Romania, for all the analyzed cases, very high values for this indicator. The analysis of the distribution of rates by living environments shows, for the rural environment in Romania a value of $26.1 \%$, the highest of the EU member states (the registered minimum being between $0.2 \%$ and $0.4 \%$ ), a situation that it is the consequence of the limited access to utilities of the houses in Romania (running water, bathroom, shower, toilet inside the house). We also emphasize that all age categories considered in Romania are affected by severe housing deprivation, the rates having maximum values at the level of the EU, which indicates that dwellings, in Romania, meet at least one criteria for inclusion in the category of deprivation. For example, four out of ten Romanians live in homes without a bathroom, shower, toilet inside $25.6 \%$ and only $2 \%$ in the EU); no toilet inside $(27.7 \%$ compared to only $2 \%$ in the U.E.); and one in 10 lives in homes with damaged roofs, walls, floors and windows $(10.1 \%)$, these values include Romania in the sphere of states with poor housing.

\subsection{Comparative analysis of the main indicators of housing affordability}

Housing costs are the main expense for many European households. In According to the information provided by Eurostat, these expenses include payments for rental interests or mortgages, but also costs for utilities such as water, electricity, gas, or heating.

In 2018, the average value of the housing cost overburden rate (the expenses represent more than $40 \%$ of the equivalent disposable income), in the EU and Romania, was $10.3 \%$, which means that a European out of ten (and also a Romanian out of ten) spends more than $40 \%$ of own income to cover housing costs. If the value of the expenses is related to the people whose earnings are below $60 \%$ of the national average income, the value of the burden rate increases, reaching 38\% at EU level and 33.3\% in Romania.

It should be noted that, during the analyzed period, both in the EU and in Romania, the share of households affected by housing expenditures decreased. These decreases are higher in the case of Romania, especially in the case of the population included in the second (from 20.3\% to 8.1\%) and in the third income quintile (from $9.2 \%$ to $4 \%$ ). In the EU case, there has been a slight increase in the overburdened rate of living costs for the population in the first income quintile, for the other categories, the decreases, although existing, are less significant. 


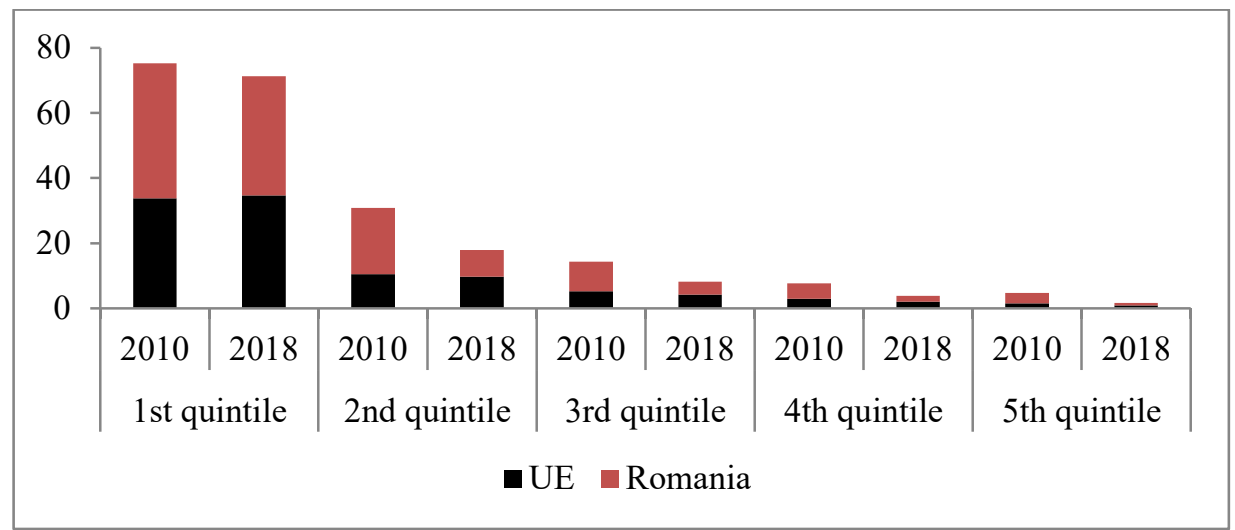

Figure no. 2. Housing costs overburden rate, by income, in Romania, and the EU (Source: own elaboration using data from EUROSTAT,www.ec.europa.eu[ilc lvho hc])

Overall, the category of the population most affected by the housing costs burden remains the category with the lowest incomes (from the first quintile), and the least affected population with high and very high earnings (last quintiles). At the level of age groups, in the EU, at least one in ten Europeans, in the age group between 18-64 years, feels housing costs as a burden, while in Romania at least one person over 65 years is in this situation. The analysis of the population distribution according to the share of housing expenses from the total household income shows that, at EU and Romania level, $25 \%$ of the population spends over a quarter of the income for housing; $10.3 \%$ over $40 \% ; 4.5 \%$ over $50 \%$; more than $3 \%$ over $70 \%$. More than half of single-person households, existing in the EU and Romania, use over $25 \%$ of income for housing expenses; more than a quarter of these households affect $40 \%$ of the income of these expenses, while $20 \%$ use more than $60 \%$ of the income for the maintenance of the house.

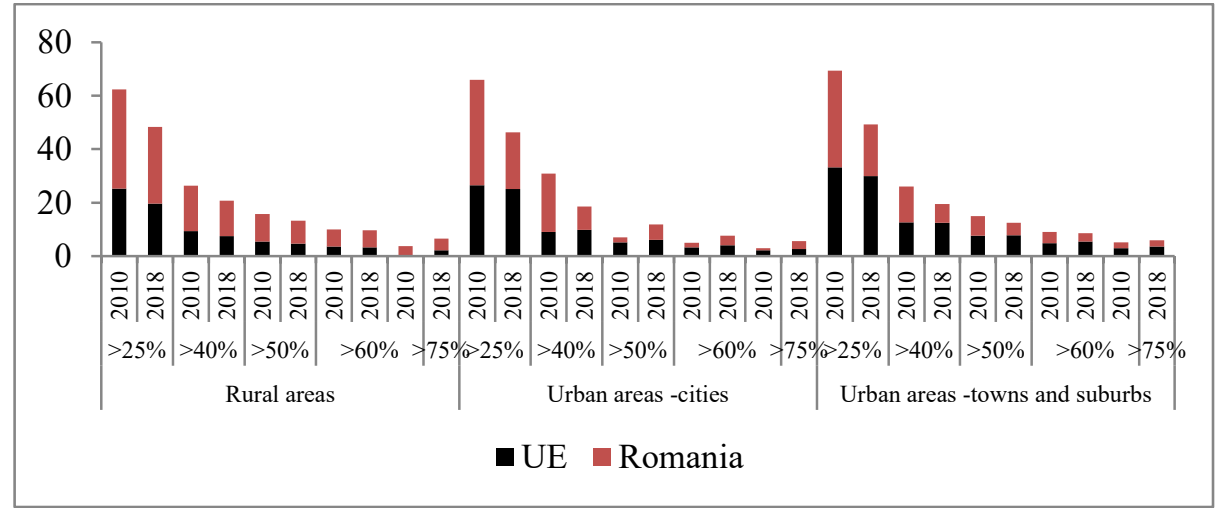

Figure no. 2. Distribution of the population according to the share of the housing cost in the total income of the household, by residence area, in the EU and Romania (Source: own elaboration using data from EUROSTAT:www.ec.europa.eu[ilc lvho29]) 
We must also emphasize that the situation of the housing burden costs has seen an improvement in 2018 compared to the situation registered in 2010, both in the EU and in Romania, a situation marked, generally by the decrease of the values of the burden rates.

However, in this context, the share of the population that feels strongly the burden of housing spending has increased in rural areas of Romania (a higher share by $0.9 \%$ uses over $60 \%$ of household income), an increase with values between $0.2 \%$ and $0.8 \%$ can be noticed for the population in the EU and in Romania living in big cities (the values, in this case, have doubled, even tripled).

This situation is illustrated by the increase of total housing costs (expressed in PPS) both at the EU level, from 445.8 in 2010 to 468 in 2018, and in Romania from 141.4 to 174.4 . The purchasing power standard (abbreviated PPS) is an artificial currency unit. Theoretically, a single PPS can buy the same amount of goods and services in each country. However, taking into account cross-border price differences means that different quantities of units in national currency are needed for the same goods and services, depending on the country [4].

Statistical data on the share of housing costs in disposable household income [4] indicate that European spends, on average, $1 / 5$ of his or her income on housing. People who own a dwelling and earn less than $60 \%$ of the national average earnings, spend more than a third of their disposable income on housing (41\% in the EU and $36.1 \%$ in Romania), while people with high earnings spend less $(16.9 \%$ in the EU and $15.2 \%$ in Romania). In the case of renting, the amount of rent is added to the cost of housing which explains the increase, at the EU level, of the share of housing expenditure in total income to $24.9 \%$.

The financial burden of the total housing cost refers to the percentage of people in the total population living in a dwelling where the costs of housing, including repayment of mortgage loans (rate and interest) or rent, insurance and service expenses (wastewater disposal, disposal) waste, regular maintenance, repairs, and other expenses). [4] Thus, on average, three out of ten households in EU Member States experience a heavy financial burden due to housing costs $(29.2 \%$ in the EU and $27.5 \%$ in Romania); almost five households in the EU, and seven in Romania, fall into the category of households with financial burden caused by housing costs (45.9\%, respectively $66.5 \%$ in Romania - maximum value for EU member states); almost three out of ten households in the EU fall into the category of households that do not feel the burden of housing costs, in Romania this group has values of $6 \%$. 


\section{Discussions}

Housing is at the heart of the concerns of European citizens, who aspire to a better quality of daily life. This often means not only that they own a home, but that they live better. It also means that the cost level of housing should not be a burden. Ensuring access to adequate housing is often a precondition for the exercise of many other fundamental rights, which every individual must enjoy [6]. Every citizen of every EU Member State deserves the right to a decent standard of living, including the key to a comfortable home. Affordable housing is recognized by the United Nations as a fundamental human right: "Citizens should be able to expect affordable housing so that the cost of housing does not compromise other human rights" [7]. Unfortunately, several aspects that characterize today's society lead to an increase in the percentage of income that must be allocated to housing costs. Among these factors, we mention the increase in housing demand in parallel with the decrease in public investment allocated to housing development; increasing the production costs of housing; increasing incomes inequality and the share of the population at risk of poverty; accentuation of material deprivation; lack of land for residential development in large cities which leads to higher housing prices and increased housing costs. The states of the European Union registered average annual growth rates differentiated, a common element with Romania is that the number of new homes is below the current level of consumer demand. [7] Although, at present, the housing stock of Romania is not burdened by major problems from the perspective of the number of dwellings, the living space and the number of rooms. In Romania, the increase in the number of dwellings occurred due to the decrease in the number of the resident population and the increase in the number of emigrants, which resulted in the decrease of the occupancy rate of the dwellings. Romania registers, at the European level, as the state with the highest share of unoccupied housing. A surplus of available housing could be considered a favorable factor, which would facilitate mobility in a stable market environment, but this is not the case of Romania, where most of the houses are unoccupied, represent holiday homes (residences), are located in places where housing markets do not work, are substandard (in most cases) or unfinished housing [8].

The main problems related to the existing housing stock in Romania refer to the fact that most of it has an overdue duration of use and includes dwellings whose structure no longer corresponds to the current consumption model. The housing need in Romania is certainly driven by the need to replace and upgrade existing units. The high share of private 
property in Romania and the lack of financial resources contribute, on the one hand, to too low housing mobility in Romania, on the other hand to the existence of a housing rental market that cannot be controlled by the state, characterized by high prices which explains the increase in housing spending in cities.

The real estate market is not homogeneous, and the market of each EU member state has its characteristics. However, against the background of the increase in the demand for affordable housing, the public funds allocated to its development decreased in the period 2010-2018, constantly and insignificant proportions both at the EU and Romanian level.

Population poverty is a current problem faced by many European countries, Romania is among the EU member states with high shares of the population at risk of poverty, social exclusion, and material deprivation. Population rate with a poverty risk for the EU-28 shows considerable variations in the EU Member States and indicates, in fact, in Romania onefifth or more of the population is at risk of poverty, which also has major implications for housing affordability. During the analyzed period, the costs of living in cities doubled or tripled due to the increase in the price of utilities, and the population's access to affordable housing decreased accordingly.

\section{Conclusions}

Compared to the existing situation at European level, a number of problems can be highlighted in Romania, which contributes to diminishing the population's access to affordable housing. The Romanian population lives in outdated dwellings, the smallest in size, characterized by the most limited access to utilities and the highest value of the overcrowding rate within the EU. The high share of private property over housing is a factor that negatively influences the condition, quality and image of housing as it limits the ability of authorities to get involved in their maintenance. The large number of vacant dwellings that deteriorate, over time, correlated with the long age of housing and poor endowment are realities make Romania stand out within the EU through the highest rates of severe deprivation of housing, overcrowding housing indicators that are responsible for reducing the accessibility of housing at national level.

The ratio of housing expenditures to income provides another perspective, not even favorable for the population's access to adequate, quality housing. The low level of development of the Romanian economy compared to that of many EU Member States is directly reflected in the 
income of the population and on the capacity of households to support housing costs. The fact that two out of ten Romanians are exposed to the risk of poverty explains the difficulties faced by the population to ensure adequate housing and well-being in life.

The research undertaken leads to the conclusion that, although the situation has improved in the last decade, in Romania, the burden of the population with housing costs is among the highest in Europe, being surpassed by only a few states. Some arguments that support this claim are: the growing share of the population that spends over $40 \%$ of the income for housing; overburdening the living costs of the rural population; housing costs excessively replace other expenses for seven out of ten households in Romania; severe deprivation of housing of the population if we take into account the income, the means of residence and the age groups. All the analyzed indicators clearly indicate that housing expenditures tend to include an increasing share of the total income of households in Romania and the EU.

\section{Acknowledgment}

This work is supported by project POCU/380/6/13/125040, entitled "Development of the tertiary university education to support the economic growth - PROGRESSIO", co-financed by the European Social Fund under the Human Capital Operational Program 2014-2020.

\section{References}

[1]. Stephen Ezennia I, Hoskara SO. Methodological weaknesses in the measurement approaches and concept of housing affordability used in housing research: A qualitative study [Internet]. PloS ONE. 2019 Aug; 14(8):1-27.

[2]. Howenstine EJ. Attacking housing costs: foreign policies and strategies. New Brunswick,N.J.: Center for Urban Policy and Research; 1983: 133.

[3]. Dorokh E, Torluccio G. Housing Affordability and Methodological Principles: An Application.[Internet] International Research Journal of Finance and Economics. 2011; 79:64-78. Available from: https://www.researchgate.net/publication/286747360

[4]. Eurostat, Appsso.eurostat.ec.europa.eu. 2020 [online]. Available from: https:/ / ec.europa.eu/.../european-union-statistics-on-income-andliving-conditions 
[5]. Pittini A. Housing affordability in the EU. Curent situation and recent trends. [Internet]. CECODHAS Housing Europe's Observatory, 2012 Jan, 5 (1): 1-11.

[6]. Dan A., The housing accesion in Romania, today. [Internet] Calitatea Vieții. 2003; XIV (3-4): 409-430. Available from: http://www.revistacalitateavietii.ro/2003/CV-3-4-2003.pdf

[7]. Build Europe Organistion. Housing: The European Challenge. A new strategy, [online]. Available from: www.buildeurope.net.

[8]. Alpopi C, Iacoboaea C, Stănescu A. Analysis of the Current Housing Situation in Romania in the European Context, Transylvanian Review of Administrative Sciences, 2014 Jan, 10(43E): 5-24. Available from: https://www.researchgate.net/journal/18422845_Transylvanian_Revie w_of_Administrative_Sciences 